\title{
A COMPLEXIDADE DA TRADUÇÃO JURÍDICA, SEUS DESAFIOS E SUA FUNÇÃ̃ ${ }^{1}$
}

\section{Cínthia Tufaile}

\section{Introdução}

Como resultado da globalização, das relações internacionais, da livre circulação de pessoas e bens e da necessidade de regular a vida em sociedade através do direito, principalmente de forma escrita, têm aumentado consideravelmente, nos últimos anos, as demandas por traduções jurídicas. Organismos internacionais como a Organização das Nações Unidas (ONU), a União Europeia (UE) ou a Organização dos Estados Americanos (OEA), entre outros, necessitam constantemente de traduções. Aliás, estas organizações internacionais, baseadas no artigo 33 da Convenção de Viena que trata da interpretação de tratados autenticados em duas ou mais línguas, adotam o princípio de que um tratado elaborado em duas ou mais línguas, possui o mesmo valor e autenticidade em cada uma delas, a não ser que se determine de forma expressa ou por concordância entre as partes, a prevalência de um determinado texto. São os chamados textos autênticos.

A tradução jurídica envolve assuntos bastante complexos e uma terminologia específica. Qualquer "erro" na tradução pode representar uma perda significativa de dinheiro, se o que está sendo traduzido é um contrato, por exemplo, ou a perda de um direito, quando se trata da tradução de uma carta rogatória. Exige-se do tradutor um conhecimento preciso do sistema jurídico e do contexto cultural do país da língua em que o documento de origem foi escrito. As estruturas e os sistemas jurídicos podem diferir significativamente de um país para outro, reflexo das diferenças culturais, linguísticas e legais. Portanto, é difícil para o tradutor encontrar equivalentes exatos na língua-alvo.

Entretanto, a proximidade das línguas e dos sistemas jurídicos pode também dar uma falsa impressão de que os obstáculos presentes na tradução serão mais facilmente

\footnotetext{
${ }^{1}$ Este artigo foi elaborado a partir da monografia apresentada como trabalho de conclusão de curso de Letras - Tradução/Espanhol, em 07 de julho de 2014, que recebeu o título: "As Agruras da Tradução Jurídica com Linguagem de Gênero: Uma Perspectiva Funcionalista", sob a orientação da profa. M.Sc. Sandra María Pérez López.
} 
TUFAILE - A complexidade da tradução jurídica...

transpostos. Além disso, essa aproximação não garante que os aspectos culturais presentes no texto original sejam satisfatoriamente transmitidos. Por isso, grande parte da complexidade da tradução jurídica está centrada na cultura e nas dificuldades que esta pode apresentar para o tradutor.

A tradução de textos jurídicos abrange uma série de documentos que podem estar diretamente vinculados com o cotidiano das pessoas, como documentos pessoais (documento de identidade, certidão de nascimento, de casamento, de óbito, histórico escolar, etc.) ou com relações entre Estados (tratados e convenções, contratos bilaterais, legislações, pedidos de extradição, entre outros).

Em uma área tão vasta, com uma volumosa produção de textos, e que regula a relação entre particulares, entre particulares e Estado e entre Estados, entendemos que a tradução jurídica não se limita ao conhecimento de terminologia específica ou linguagem própria do direito, mas exige do tradutor um comprometimento maior para identificar e ponderar sobre as diversidades culturais existentes entre o texto de partida e o de chegada, permitindo a tomada de decisões adequadas no processo tradutório.

Assim, este artigo propõe apresentar algumas considerações sobre a complexidade da tradução jurídica, seus desafios e sua função. Com esse propósito, abordaremos inicialmente os vínculos existentes entre direito e tradução, e na sequência as especificidades da linguagem jurídica, as características apresentadas por essa linguagem e alguns desafios que podem surgir durante o processo tradutório.

\section{Direito e Tradução}

$\mathrm{O}$ direito tem por objetivo responder às necessidades de ordem e justiça de cada sociedade. E justamente por isso ele não é universal, ou seja, não atua do mesmo modo sobre todos os povos, em todas as épocas ou lugares. O direito é fenômeno cultural com a mesma extensão de peculiaridades quanto são as variantes culturais de uma determinada sociedade. Consequentemente, não pode haver sociedade sem direito, já que todo grupo social necessita de um mínimo de ordem, para a convivência pacífica e para solução de conflitos. E o direito, com seu caráter imperativo, atende a essa necessidade fundamental à sociedade. Na lição de Graneris, mencionado por Betioli (2010, p. 9): "Não é porque o homem precisa do direito que ele vive em sociedade; antes, ele vive em sociedade e, por conseguinte, ele tem necessidade do direito. Se a 
sociedade é o fim, o direito é o meio. O homem suporta o jugo do direito porque a sociedade o postula."

Também não pode existir direito sem sociedade, pois ele é produto da sociedade na qual foi criado e vive em função dela, sendo inconcebível sua existência fora do ambiente social, devido a sua responsabilidade de criar normas a partir dos valores que a sociedade elege como fundamentais. Logo, sofre a influência do tempo e do espaço, e está em constante transformação, já que os valores igualmente se modificam.

A diversidade dos grupos sociais gerou sistemas jurídicos distintos compostos por leis, costumes e jurisprudência do direito positivo vigente em diversos países. Assim, cada Estado soberano adota um sistema jurídico próprio, de acordo com o meio social no qual o direito está inserido. Os sistemas jurídicos podem ser classificados em cinco sistemas, sendo dois os mais predominantes no mundo: Civil Law e Common Law.

O Civil Law é o sistema mais antigo, fundado no direito romano e caracteriza-se por seu caráter positivo, com normas gerais e escritas, que devem ser aplicadas nos casos concretos. A principal fonte do direito é a lei. Este sistema está presente em todos os continentes, com especial supremacia na Europa e na América Latina. Já o Common Law é um sistema originário da Inglaterra medieval e pertence a países de língua inglesa. Tem como características a tradição oral e decisões baseadas nos costumes e na jurisprudência, ou seja, na análise de sentenças de casos análogos.

Como já afirmado na introdução deste artigo, a linguagem jurídica, a pluralidade de sistemas jurídicos, a dimensão cultural do direito e o contexto em que esse é produzido, constituem elementos que tornam a tradução jurídica um dos tipos mais complexos de tradução.

No campo da ciência, a tradução é "favorecida" pelo fato dessa área geralmente possuir uma terminologia única; assim, os termos utilizados dentro desta linguagem pretendem excluir a possibilidade de qualquer ambiguidade. Os símbolos químicos e os nomes científicos, por exemplo, possuem uma representação universal, e, portanto, não são afetados por problemas de contexto ou linguagem. Já os conceitos e a terminologia do direito nem sempre possuem a mesma correspondência dentro das diferentes sociedades e dentro dos diversos sistemas jurídicos. O discurso presente no direito carrega uma dimensão cultural que se reflete não só nas palavras e termos específicos.

Ainda que muitos teóricos sustentem que a dificuldade da tradução jurídica reside na diversidade dos sistemas jurídicos e línguas diferentes, Jean-Claude Gémar, 
TUFAILE - A complexidade da tradução jurídica...

professor e pesquisador em tradução jurídica da Université de Génève argumenta que não se deve subestimar os obstáculos apresentados pelas línguas e culturas "irmãs" (2005b, p. 43). "O estrangeiro é antes de tudo o vizinho", assinala Isso Camartin, citado por Gémar (2005b). Por isso, a proximidade do português e do espanhol e o fato de a maioria dos países que possui uma dessas línguas como idioma oficial adotar o Civil Law como sistema jurídico oficial não impede que conceitos jurídicos tomem acepções diferentes.

Sendo o direito uma ciência social, o fenômeno que ele descreve dificilmente é transferido de uma língua a outra ou de um sistema a outro. O direito, assim como a cultura, é um processo hermenêutico que tem sua própria linguagem. O direito é, portanto, tanto gerador como produto de uma cultura: ele ajuda a moldar a cultura, ao mesmo tempo, que sofre constantemente a sua influência. E, a complexidade da tradução jurídica reside exatamente nessa tentativa de intermediar dois fenômenos culturais igualmente complexos: direito e linguagem.

\section{As especificidades da linguagem jurídica e sua tradução}

Para entender melhor as especificidades da linguagem jurídica, é necessário inicialmente esclarecer o que se entende por linguagem especializada. No sentido comum, entende-se por linguagem especializada uma linguagem que apresenta características diferentes da linguagem corrente, formando um subsistema linguístico próprio e unívoco. Porém, essa visão da linguagem de especialidade elitista, utilizada somente por iniciados e especialistas de uma área, tende cada vez mais a desaparecer, sendo substituída pelo conceito da língua comum ou natural, ou seja, a linguagem utilizada cotidianamente pelas pessoas, aplicada em uma situação de uso especializado.

A linguagem especializada utiliza-se do mesmo repertório fonológico, morfológico e sintático da linguagem comum, que em contextos específicos assumem outro significado, sendo utilizada por interlocutores de diferentes hierarquias e graus de especialização em diferentes níveis de formalidade.

Segundo Gémar (2005b, p. 43) o conceito de língua especializada ainda é um tema controvertido entre os teóricos da linguística, mas sua utilização é cada vez mais constante, em razão do interesse despertado entre os especialistas em linguagem e o uso generalizado entre as diversas áreas do conhecimento. Para ele, 
Em teoria, o princípio da língua de especialidade é um dos mais simples: cada área possui sua língua, sua maneira de pensar as coisas, e as palavras como expressá-las. Um cardiologista, um físico, um geólogo ou um biólogo possuem e utilizam, sem dúvida, uma língua própria e até exclusiva da sua área. Utilizam um vocabulário especializado, jargão técnico ou profissional, mais ou menos desenvolvido de acordo com a disciplina, mas também palavras da língua comum com uma acepção singular, geralmente opaca à compreensão do leigo. (tradução nossa)

Hoffmann (1988, p. 81) apresenta a seguinte definição de linguagem especializada:

é o conjunto de todos os recursos linguísticos que são utilizados em um âmbito comunicativo, delimitado por uma especialidade, para garantir a compreensão entre as pessoas que nela trabalham. Esses recursos conformam, enquanto sublinguagem, uma parte do inventário total da língua. Na composição de textos especializados, sua seleção e estruturação estão determinadas tanto pelo conteúdo especializado quanto pela função ou finalidade comunicativa do enunciado, assim como também por uma série de outros fatores objetivos e subjuntivos presentes no processo comunicativo.

Assim, a linguagem especializada partilha de todas as características da linguagem comum e utiliza o mesmo padrão, ainda que alguns elementos sejam favorecidos de maneira particular. Por isso, mesmo que um grupo fechado de especialistas utilize recursos léxicos e gramaticais diferentes dos não especialistas, teoricamente, essas opções linguísticas estão disponíveis a qualquer usuário de uma mesma língua, independentemente de seus conhecimentos ou área de atuação.

Isso não significa que a linguagem especializada não possua determinadas peculiaridades, mas o ponto central dessa especialização reside no contexto de uso e está intrinsicamente associada à competência do falante. Em situações marcadas pela especialização, o falante ativa os traços adequados a ela e prescinde daqueles que não são pertinentes ou adequados.

Nesse contexto, a linguagem jurídica nada mais é que a utilização da língua natural com peculiaridades próprias de uma comunicação especializada. Essas peculiaridades derivam do caráter prescritivo do direito, que determina normas de conduta, dita leis e impõe sanções em caso de inobservância ou descumprimento.

Como já dito anteriormente, existe uma forte ligação entre direito e linguagem, já que através desta os conceitos jurídicos ganham forma e são transmitidos, seja de forma oral ou escrita. No entanto, é preciso recordar que o usuário da língua comum também faz uso do léxico jurídico, sem necessariamente, ter propósitos jurídicos. Termos aparentemente jurídicos são utilizados cotidianamente, porém possuem significados 
diferentes para o leigo e o especialista, como: lei, justiça, vida, assassinato, filho, pai, mãe, entre outros.

O caráter plurifuncional e pluridimensional do direito é abordado da seguinte forma pelo jurista e professor francês Gerard Cornu: "O direito tem mil bocas que não correspondem somente às fontes propriamente ditas do direito (a lei e seus textos, os costumes em seus aforismos, as máximas e adágios), mas a todas as vozes que se mesclam na criação e realização do direito.” (2000, p. 218 - tradução nossa)

Neste sentido, podemos conceber o direito e consequentemente a linguagem jurídica como o produto de uma determinada cultura, na qual estão refletidos costumes, comportamentos, valores e a visão de mundo de uma sociedade. O aspecto cultural está codificado no texto jurídico, podendo ser verificado em seu discurso e na terminologia utilizada, exprimindo conceitos e empregando formas específicas de uma cultura.

Desta forma, podemos afirmar que dentro da cultura geral existe uma cultura jurídica composta por ideias, valores e atitudes que uma sociedade utiliza para organizar seu ordenamento jurídico. A cultura de uma sociedade determina as condutas de seus indivíduos e dita a norma jurídica e também os efeitos dessas normas no grupo social. Como declara Gémar (2005a, p.2), "Cada povo, segundo a sua cultura, seus usos e costumes, forjou sua própria tradição de redação dos textos jurídicos.” (tradução nossa)

Por seu aspecto multicultural, a linguagem jurídica não é homogênea nem unívoca, mas se realiza em diferentes tipos de textos, elaborados por diversos autores e dirigidos a vários destinatários.

Gérmar (2005b, p. 49) afirma que o texto jurídico terá uma maior ou menor bagagem cultural de acordo com seu autor e os respectivos destinatários. Nesse sentido, divide os destinatários em quatro grandes categorias, que vão da menor à maior instrução:

1) O leitor leigo com maior ou menor especialidade;

2) O leitor especialista;

3) O jurista profissional

4) O erudito

Dependendo do leitor do texto jurídico, "seu conteúdo jurídico (a linguagem da natureza) será mais ou menos compreendido, mas o fundamento cultural (ou sociocultural: a linguagem da cultura), salvo exceções, escapará quase completamente 
ao leitor da primeira categoria, em parte ao leitor da segunda categoria e até da terceira." (p. 50 - tradução nossa)

A linguagem jurídica como linguagem de especialidade possui algumas características próprias (léxico, sintaxe, semântica e estilo) que a diferem de outras áreas do conhecimento. Em geral, essa linguagem se caracteriza pelo alto grau de formalidade, por sua natureza abstrata, pela impessoalidade e pela autoridade em que se expressa. Em textos escritos, também encontramos características próprias de acordo com o tipo de texto elaborado. Assim, um contrato possui uma estrutura diferente de uma lei que, por sua vez, é diferente de uma sentença. Considerando que não existe um conceito universal para linguagem jurídica e que esta possui propriedades diversas de acordo com o sistema jurídico, o ordenamento jurídico e o país no qual se expressa, apresentaremos a seguir as principais características da linguagem jurídica presentes no português e no espanhol, mas também existentes em outras línguas.

\section{- Características lexicais}

O léxico jurídico é formado por um conjunto de termos que adquirem significado ou sentido dado pelo direito em um determinado ordenamento jurídico. O léxico jurídico complexo é uma característica marcante da linguagem jurídica.

Gerárd Cornu, autor da obra Linguistique Juridique (2000, p. 62), divide os termos da linguagem jurídica em dois grupos:

a) Termos criados especialmente para expressar conceitos jurídicos e inexistentes em outros campos;

b) Termos retirados da língua comum e que adquiriram a especificidade da área.

A partir dessa divisão, o autor elabora uma tabela com exemplos de termos jurídicos classificados nessas duas categorias. O primeiro está relacionado com termos de uso exclusivo na área jurídica e o segundo abrange tanto os que são usados na língua comum como na especializada. Aproveitamos a mesma tabela para colecionar alguns exemplos de termos existentes na língua portuguesa:

\begin{tabular}{|c|c|c|c|}
\hline \multirow{2}{*}{$\begin{array}{l}\text { Termos jurídicos por } \\
\text { excelência: } \\
\text { Tipificação, } \\
\text { derrogação, } \\
\text { parricídio, avalizar. }\end{array}$} & \multicolumn{3}{|c|}{ Termos de dupla pertinência: } \\
\hline & $\begin{array}{c}\text { Termos jurídicos } \\
\text { usados na língua } \\
\text { comum: juiz, crime, } \\
\text { justiça, delito, } \\
\text { homicídio }\end{array}$ & $\begin{array}{l}\text { Termos da língua comum } \\
\text { usados com sentido } \\
\text { jurídico: domicílio, } \\
\text { matrimônio, prostituição }\end{array}$ & $\begin{array}{c}\text { Termos com o } \\
\text { sentido da língua } \\
\text { comum e } \\
\text { implicações legais: } \\
\text { Pai, mãe, filho, } \\
\text { cônjuge, morte, vida, } \\
\text { idoso }\end{array}$ \\
\hline
\end{tabular}


Cornu (id. ib.) esclarece que os termos jurídicos por excelência são minoria na terminologia do direito e que se caracterizam pela sua univocidade ou monossemia, que confere estabilidade semântica e precisão ao vocabulário jurídico. Para ele, os termos desse grupo não são importantes e o acesso ao direito não ocorre através de tais termos, atribuindo-lhes um caráter secundário. Possuindo apenas significado jurídico, fora do direito, esses termos não existem.

Além disso, o texto jurídico caracteriza-se pelos seguintes elementos:

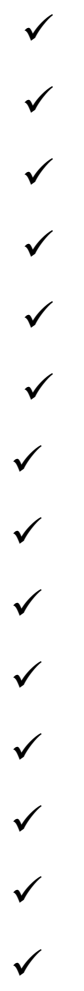

Elevado grau de formalidade;

Uso de palavras arcaicas;

Emprego de latinismo;

Uso de estrangeirismos;

Eufemismos;

Emprego de fórmulas de cortesia;

Preferência pela utilização de fórmulas fixas;

Frases longas e complexas;

Uso de maiúsculas e siglas;

Predominância da voz passiva;

Uso de pronomes indefinidos;

Emprego da terceira pessoa;

Emprego de verbos performativos;

Tempos verbais praticamente inexistentes fora do contexto jurídico.

\section{Tradução Jurídica: desafios e função}

As dificuldades da tradução jurídica e, em especial, a tradução jurídica no par linguístico português/espanhol é um campo de trabalho ainda a ser muito explorado por três aspectos: 1) a tradução jurídica é um campo relativamente novo de estudo, sendo que sua importância passou a ser valorizada a partir do fenômeno da globalização; 2) a crença ilusória da proximidade entre o português e espanhol; e 3) e a predominância da língua inglesa, em relação às demais línguas, focando grande parte dos estudos da tradução, principalmente a especializada, em torno deste idioma.

Tendo o inglês como idioma fonte ou destino, os estudos sobre a tradução jurídica se concentram na dificuldade de traduzir de um sistema jurídico a outro, ou seja, do 
TUFAILE - A complexidade da tradução jurídica...

Civil Law para o Commow Law e vice-versa, sendo que o primeiro tem como fonte principal do direito, a lei, e o segundo, a jurisprudência baseada nos costumes e tradições.

Sem dúvida, essa transposição apresenta dificuldades e o tradutor, como mediador intercultural, deve estar atento e buscar soluções que lhe permitam vencer essas dificuldades. Porém, a tradução entre línguas próximas e/ou dentro do mesmo sistema jurídico não significa uma tarefa mais fácil. Isso porque mesmo possuindo a mesma raiz latina, cada língua apresenta características próprias no aspecto lexical, sintático e semântico. Essas peculiaridades produzem falsos cognatos e construções frasais pretensamente iguais, que podem acarretar sérios problemas à tradução. Assim, o termo "estafa" em espanhol, por exemplo, não significa cansaço, fadiga, esgotamento, como em português, mas sim, fraude.

Embora os ordenamentos jurídicos da Espanha e dos países da América Latina pertençam à mesma família, a romano-germânica, a tradução jurídica deve observar a instituição responsável pelo texto (se é de natureza jurisdicional, doutrinária ou normativa), suas imposições ideológicas, seus aspectos sociohistóricos e culturais, além da linguagem natural presente no texto, que se mescla com a linguagem jurídica, fornecendo elementos para a construção de um texto especializado. Ademais, é necessário considerar o aspecto flutuante do significado das palavras devido à natureza das diferentes instituições e à diversidade de conceitos entre as nações. A própria língua espanhola na América é multifacetada pelas variedades nacionais dos países nos quais ela é o idioma oficial, e não é sequer idêntica ao espanhol utilizado na Espanha. É importante também destacar o fato de ainda que pertencendo ao mesmo sistema jurídico, cada país ter seu ordenamento jurídico próprio em consonância com as necessidades da sociedade na qual o direito está inserido.

Outro fator a ser considerado é que a tradução jurídica lida com mundos reais diferentes, ou seja, não se trata simplesmente de uma visão de mundo diferente em função da língua, é o próprio referente que é divergente. Estamos falando da confrontação de duas culturas jurídicas, cada uma com suas particularidades e seus termos específicos, ainda que pertencentes ao mesmo sistema jurídico. Às vezes, existe um equivalente idêntico na outra cultura, em outros momentos, um equivalente comparável, mas com diferenças significativas e, muitas vezes, não existe nenhum 
equivalente. Ou seja, não há equivalente linguístico, quando comparadas culturas jurídicas diferentes, nem naquelas que empregam a mesma língua.

Gémar (2005b, p. 59) expressa bem a difícil responsabilidade do tradutor de textos jurídicos: "espera-se que [o tradutor jurídico] alcance a improvável síntese entre a letra do direito que contém o texto e o espírito do sistema que o rege, tudo isso expressando no texto de chegada a mensagem do texto de partida, segundo os cânones da linguagem do direito do destinatário.” (tradução nossa)

Os países regulam as relações entre seus indivíduos, entre os indivíduos e o Estado e entre os Estados através do direito. Essa regulamentação ocorre através de leis, acordos, contratos, sentenças, testamentos, entre outros. Apesar de todos esses textos pertencerem ao universo jurídico, eles possuem características e funções diferentes, tanto na forma como no conteúdo.

Observar as características, a função do texto, seu emitente e seu destinatário, é fundamental para uma tradução bem sucedida. Assim, podemos classificar os textos jurídicos em dois grandes grupos:

a) Textos que têm função apenas informativa, de levar ao conhecimento de outra sociedade normas jurídicas definidas por um determinado país;

b) Textos que terão validade jurídica com a respectiva assinatura das partes envolvidas ou a partir da sua publicação.

No primeiro grupo encontramos um grande número de textos que têm por objetivo informar, orientar ou exemplificar como determinadas condutas sociais são reguladas por um país, ou suprir um vácuo da legislação local. Esses textos não tem validade jurídica na sociedade para a qual foram traduzidos, visto que carecem de outras ferramentas jurídicas (leis, códigos, decretos) para sua validade. De forma geral, as normas jurídicas só têm validade dentro do Estado no qual são produzidas, seguindo o princípio locus regit actum (o ato é regido pela lei local). É a especificidade de cada nação e de cada cultura que determina o que vai ser valorizado ou defendido pela sociedade mediante regras jurídicas.

O segundo grupo abrange, em sua maioria, os acordos bilaterais firmados entre países, cuja língua de redação está regulamentada pela Convenção de Viena; documentos emitidos por organizações internacionais como a ONU, OEA, UE, etc.; litígios envolvendo dois ou mais Estados, ou indivíduos de Estados diferentes; e 
TUFAILE - A complexidade da tradução jurídica...

contratos firmados entre particulares, que deverão ter validade jurídica em seus respectivos países.

Neste sentido, podemos afirmar que a tradução jurídica tem em síntese duas finalidades: a informativa que serve como referencial, como suporte ou orientação para suprir lacunas na legislação de um país, demonstrando como casos análogos são julgados tanto em sistemas jurídicos diferentes quanto iguais e em ordenamentos jurídicos diferentes, e apresentando novos posicionamentos doutrinários; e uma outra finalidade, que é fazer valer como instrumento legal na cultura-meta o documento traduzido.

\section{Considerações Finais}

Procuramos neste artigo traçar algumas considerações a respeito da tradução de textos jurídicos, sobre as características da linguagem jurídica, os desafios que podem se apresentar para o tradutor durante a realização do seu trabalho e as funções que esse tipo de tradução pode ter.

Acreditamos que a tradução de textos jurídicos apresenta um elevado grau de dificuldade que transcende o conhecimento da terminologia e da gramática, em razão das variáveis culturais presentes neste tipo de texto, e por abranger objetos tão complexos como cultura e direito, exigindo do tradutor reflexões preliminares e definição de estratégias para o sucesso do seu trabalho, sendo que sua tarefa reside em intermediar duas culturas, dois ordenamentos jurídicos, duas línguas, através de uma prática consciente e reflexiva.

\section{Referências bibliográficas}

BETIOLI, Antonio Bento. Introdução ao Direito. São Paulo: Saraiva, 2010. 607 p.

CORNU, Gerárd. Linguistique Juridique. Paris: Monchrestien, 2000. 412 p.

GÉMAR, Jean-Claude. De la traduction (juridique) à la jurilinguistique. Fonctions proactives du traductologue.2005(a). META: Journal des Traducteurs. Disponível em: <http://www.erudit.org/revue/meta/2005/v50/n4/019840ar.pdf >. Acesso em: 22 maio 2014. 
Jean-Claude. La Asimetría Cultural y el Traductor Jurídico. El lenguaje del derecho, la cultura y la traducción. In: MONZÓ, Esther; BORJA, Anabel (Ed.). La traducción y la interpretación en las relaciones jurídicas internacionales. Casteló de La Plana: Universitat Jaime I, 2005(b). p. 33-62.

GONÇALVES JUNIOR, Jerson Carneiro; GONZÁLEZ, Patricia Varela. Curso de Español Jurídico. Rio de Janeiro: Elsevier, 2011. 211 p.

HOFFMANN, Lothar. Conceitos Básicos da Linguística das Linguagens Especializadas. Tradução: Maria José Bocorny Finatto. Disponível em: <http://www.ufrgs.br/termisul/oa/arquivos/conceitos_linguistica.pdf $>$. Acesso em: 22 maio 2014.

Decreto $n^{\circ} 7.030$, de 14 de dezembro de 2009. Convenção de Viena Sobre o Direito dos Tratados. Brasília, DF, Disponível em: <http://daimre.serpro.gov.br/legislacao/convencao-de-viena-sobre-o-direito-dos-tratados1/>. Acesso em: 10 abr. 2014. 